\title{
Providing a Peaceful Passage through Care, Comfort, and Compassion
}

\author{
Karin L Ciance* \\ Assistant Professor of Nursing, Anna Maria College, USA
}

*Corresponding author: Karin L Ciance, Assistant Professor of Nursing, Anna Maria College, USA.
Received Date: April 24, 2019

Published Date: May 20, 2019

\begin{abstract}
Advocating for hospice care for your loved one sooner than later can help provide a peaceful passage. When faced with the need to address end of life patients, families and loved ones this will require a multidisciplinary approach of care and support. Nurses, particularly novice nurses and newer graduates are not comfortable addressing the need to discuss or explore planning for end of life care options. In today's high-tech society, from my observations the basic needs of nursing care are somewhat lacking. Therefore, the development of the $3 \mathrm{C}$ 's which include: caring, comfort and compassion should be utilized in all patient care situations but particularly in end-of-life hospice care. My theory is that the nurse who embraces the $3 \mathrm{C}$ 's who provides direct care and coordinates the members of the interdisciplinary team to augment part or all of the $3 \mathrm{C}$ 's will thus assist the individual and family to both a peaceful and meaningful death.

As a nurse educator for prelicensure nursing students, I have expanded this care approach to end-of-life hospice care during the Community Health Nursing course using case studies. These case studies have been used in pre and post clinical conference discussions and during class to augment theory presentation to prepare the nursing student for the hospice experience. One common theme that continues to surface in my practice is that often clients referred to hospice services stated they do not regret it, but rather wish they had started sooner. Hospice provides care, comfort, and compassion to everyone; thus supporting a peaceful passage and death with dignity.
\end{abstract}

\section{Providing a Peaceful Passage through Care, Comfort and Compassion}

Advocating for hospice care for your loved one sooner rather than later can help provide a peaceful passage. As nurses, we need to educate the patient and family members during their illness, when the treatment is no longer working, or when the treatment has completed, and the person's health and longevity cannot be extended with further interventions. Quality of life versus quantity of life needs to be addressed with the loved one before they are days away from death. Engaging the hospice care team will provide beneficial care, comfort and compassion to the entire family. .

Who can benefit from hospice care? According to Bernazzani [1]. Individuals who have been diagnosed with a terminal illness and are medically certified as having a life expectancy of six months or less can receive this type of care. For hospice care to be covered, a patient must decline curative treatments and elect symptom management and comfort care instead (para. 5).

Other life events, for example the birth of a baby, families actively engageinmakingplansforthissignificantlifeevent.Thereisalotoftimeand attention devoted to planning for and celebrating the birth of a new life. Certain choices are made, supported and respected by the new mother and families involved. There is not this level of preparation or view held towards end of life care and needs. When faced with the need to address end of life patients, families and loved ones will require a multidisciplinary approach of care and support. Mutual decision making to not prolong life and seek comfort care is important and can be difficult. Advanced directives will guide the decision-making process. Serving as an advocate, team leader, provider of hands-on-care, the nurse has a crucial role in ensuring the patient receives necessary care during this challenging stage of life.

Preparation for this role begins in a nurse's foundational education for practice. However, although this is an essential component of nursing education curriculums, it can become an underappreciated concept in the high-tech/low-touch health care environment. Nurses, particularly novice nurses and newer graduates are not comfortable addressing the need to discuss or explore planning for end of life care options. Nursing education and 
nursing has lost a valuable practice concept as defined by Virginia Henderson. Henderson's (1966) definition of nursing practice states: The unique function of the nurse is to assist the individual, sick or well, in the performance of those activities contributing to health or its recovery (or to peaceful death) that he would perform unaided if he had the necessary strength, will or knowledge. And to this in such a way as to help him gain independence as rapidly as possible as cited in Ahtisham \& Jacoline [2].

Virginia Henderson focused on individual care. She described the nursing role as assisting individual's with essential activities to maintain health, to recover, or to achieve peaceful death [2].

As a new graduate nurse over 3 decades ago from a diploma program, I found myself and my family being faced with the decision to make my mother a do not resuscitate (DNR). My mother, diagnosed with lung cancer at 48 , received 30 radiation treatments and several chemotherapy courses, even though there was no cure. I recall the doctor stating, "This is treatable but not curable". Nine months later at the age of 49 she passed away while being intubated and on a ventilator in the intensive care unit.

Personally, and professionally I was not well versed in available alternative care options especially the option to transfer her out of the hospital to home to receive hospice care and comfort measures only. During this time, my family lacked the knowledge and we were not provided with end of life care options. My family and my mother did not have a voice in making these choices. Unable to make these decisions for herself, we went along with what the doctors were telling us to do. In retrospect, before they were about to transfer her to the Medical Intensive Care Unit, I wished we would have had the option to take her home. We all knew she had inoperable lung cancer and that the prognosis was grave. Nurses were unable to provide her or us with the support we needed at that time to allow my mother "a peaceful death". This experience profoundly affected me personally and professionally. As I matured in my nursing practice with a community health focus, I came to the realization that the essence of what is required for high-quality individualized care is best addressed by applying the 3 C's. The 3 C's include caring, comfort and compassion should be utilized in all patient care situations but most importantly in end-of-life hospice care.

The following are examples of the how the 3 C's have been effectively utilized in end-of-life care situations:

\section{Caring}

Display a positive attitude; provide a gentle kindness and genuine caring. This would extend beyond the patient to include those family members and significant others involved in their care.

\section{Comfort}

Providing clean linens, repositioning the patient, providing pain medication, washing their hair and combing it, providing a back or foot massage, applying lotion to dry skin, cleaning and trimming fingernails, fluffing the pillow, provide a quiet relaxed environment, playing their favorite music, singing their favorite songs, and allowing those individuals important to the patient to be present.

\section{Compassion}

Holding someone hand, actively listening, and just being there to alleviate someone's distress with the situation. In today's hightech society, from my observations the basic needs of nursing care to include addressing all dimensions of the patient's care needs (physiological, psychological, sociocultural, developmental, and spiritual) are not being fully provided. My informed nursing practice position is that the nurse who embraces the $3 \mathrm{C}$ 's through the provision of direct care and coordination with members of the interdisciplinary team to augment part or all the 3 C's will thus assist the individual and family to both a peaceful and meaningful death. To achieve this much needed missing component of care, nurses should impart to patients and families the following information and services that according to The National Hospice Palliative Care Organization (2018) can provide once the care have been initiated.

The interdisciplinary hospice team:

1. Manages the patient's pain and other symptoms.

2. Assists the patient and family members with the emotional, psychosocial, and spiritual aspects of dying.

3. Provides medications and medical equipment.

4. Instructs the family on how to care for the patient.

5. Provides grief support and counseling.

6. Makes short-term inpatient care available when pain or symptoms become too difficult to manage at home, or the caregiver needs respite time.

7. Delivers special services like speech and physical therapy when needed.

8. Provides grief support and counseling to surviving family and friends [3].

During my over 3 decades of personal and professional experiences in nursing practice I have encountered numerous care situations in which the application of the 3 C's should have been initiated. These essential care components, when overlooked and not provided; result in a significant negative impact on both the patient and family/loved ones.

These experiences have further supported my practice of informing patients and family members, as well as instructing nursing students about the benefits of hospice care. Often the patients I have worked with decline the offer to be placed on hospice service as they think this means that all hope is gone, and this is the end of the road for them. I inform the patients and their families that hospice services can be discontinued if their prognosis improves and they can be placed on regular home care services.

Talking about advance directive decisions can be very difficult to discuss, because talking about death and dying is not easy. However, options need to be discussed so an informed decision can be made, and people's wishes can be respected especially when they do not want heroic measures to prolong their life. As a nurse educator for 
prelicensure nursing students, I have expanded this care approach to end-of-life hospice care during the Community Health Nursing course by using end of life care case studies. These case studies have been adapted from my own personal and professional experiences with end of life care for use in a Pre-licensure BSN nursing program.

As a nurse educator, I often refer to these case studies, instructing nursing students not to be afraid to discuss end-of-life care with their own families and patients. In addition, this past fall, I was able to secure a new clinical rotation at a long-term care center that specializes in providing outpatient hospice services in the community. During their clinical practice experience, students accompany a nurse on visits to adults and pediatric patients receiving hospice services. This proved to be an excellent experience for the nursing students to observe how hospice services are delivered to the patient in their home, reinforcing not only the principles of hospice care principles but also how the hospice team uses the $3 \mathrm{C}$ 's to deliver high-quality care. Through instructor-guided discussion of these experiences and the use of the end-of-life case studies in the classroom, the foundation has been provided for the students to incorporate this care approach into their professional nursing practice.

\section{Case Study}

\section{Case study 1}

A male patient (72) coincidently diagnosed with lung cancer was able to pass away peacefully in his home. Hospice care was recommended and initiated. He was initially reluctant about the process but then agreed to have hospice services in his home. After three days, surrounded by his loving family and myself we were able to witness him take his last breathe in his bedroom. In this case, although only three days of hospice care, he did not die in the hospital and died at home.

\section{Case study 2}

A male patient (79), diagnosed with gastrointestinal cancer, was hesitant to be placed on the hospice care team. He expressed that he liked still overseeing his care even though he was on hospice. Respect, dignity, and control were important issues that were maintained for him. He was able to pass away peacefully in his home surrounded by his loving family. The family expressed appreciation for the caring, comfort, and compassion of the hospice care team. He received hospice services for five months.

\section{Case study 3}

A female patient (81), diagnosed with small intestine cancer, was placed on hospice care during her treatment. This hospice team was fantastic, caring for all her needs, physically, emotionally, and spiritually. She was able to have a peaceful, perfect passage with her children and myself witnessing her last breath of life in her bedroom. Living through this experience provided comforting care to the family. The hospice care team continues to support the family by inviting them to a memorial mass each year.

\section{Case study 4}

A female patient (85) fell in her home, and as a result broke her leg which required surgery. She was admitted to a rehabilitation facility to recover from the surgery but developed complications. She was admitted to the intensive care unit and her prognosis wasn't favorable for a positive recovery. Knowing her wishes, the family met with the physician and all aggressive treatments were discontinued. She was placed in a hospice room at the hospital on comfort measures only (CMO). This was a learning experience for me to discover this type of a room was in an acute care hospital. The patient was from out of state and was not stable enough to be transported home in an ambulance; this was an excellent option for the family. This room had couches where family members could rest and stay all night long. Surrounded by her loving family, she died two days after being placed on CMO.

\section{Case study 5}

A female patient (97) fell in her home and suffered a massive heart attack. She was admitted to the hospital. After consulting with the physician, he suggested she be put on comfort measures only and start thinking about hospice as her prognosis was grave. I suggested she be transferred home with hospice services, but her son did not want to do this. This hospital also had a hospice room, and I requested that she be put on the waiting list as the room was occupied. After three days of CMO, she died surrounded by her loving family.

These case studies are used in pre and post clinical conference discussions and during class to augment theory presentation to prepare the nursing student for the hospice experience. The case studies are presented followed by a guided group discussion to:

1. Increase the student's understanding of the essential care concepts within the case study.

2. Clarify any misconceptions.

3. Most importantly in a safe environment, guided and supported by the instructor the student can apply the 3 C's. These essential nursing care principles can effectively be applied in actual (face-to-face, hands-on) clinical practice settings.

A few clinical practice examples from the nursing students utilizing the 3C's would include holding a dying child's hand; playing music; gently repositioning the patient with the nurse using care as to not provide them any discomfort. Feedback from the nursing students utilizing the case studies was positive, they found them helpful to prepare them for taking care of end-of-life hospice care patients in their clinical experience.

In summary, through my clinical practice and nurse educator roles, my intention is to provide the knowledge and insight regarding the importance of hospice care for nursing students, nurses and their loved ones in the future. As nurses' valuable lessons can be learned when caring for end-of-life hospice patients. 
Initiate, the $3 \mathrm{C}$ 's as soon as someone is discussing advance directive decisions to provide a foundation for high-quality nursing practice to the individual and family. In my experience, every family that has encountered the benefits of the hospice care team as expressed only positive comments about the service. One common theme that continues to surface in my practice is that often clients referred to hospice services stated they do not regret it, but rather wish they had started sooner. Hospice provides care, comfort, and compassion, to everyone thus supporting a peaceful passage and death with dignity.

\section{Acknowledgement}

I would be remiss if I did not acknowledge the person who inspired me to write this article, my mother who passed away 35 years ago. Also the other patients and families that have provided me with the insight to develop this care perspective. Furthermore, I would like to thank the nursing students who allowed me to validate and refine these care concepts.

\section{Conflict of Interest}

There is no conflict of interest.

\section{References}

1. Bernazzani S (2019) Comparing End-of -Life Care Options. Retrieved from https://www.agingcare.com/articles/comparing-end-of-life-careoptions-1981129.htm

2. Ahtisam Y, Jacoline S (2015) Integrating Nursing Theory and Process into Practice; Virginia's Henderson Need Theory. International Journal of Caring Sciences 8(2): 443-450.

3. NHPCO (2018) NHPCO Facts and Figures: Hospice Care in America. Alexandria, VA: National Hospice and Palliative Care Organization. Rev. ed.Retrievedfrom:https//www.nhpco.org/sites/default/files/public/ Statistics_Research/2017_Facts_Figures/pdf 